\title{
Contextual factors of the mathematics learning environment of grade 6 learners in South Africa
}

\author{
G.S. Kotze and J.P. Strauss \\ School of Education, Faculty of Humanities, University of the Free State, and \\ Research Institute for Educational Planning, University of the Free State \\ kotzeg.hum@mail.uovs.ac.za and strausjp.hum@mail.uovs.ac.za
}

The aim of this article is to provide insight into the personal characteristics and family backgrounds that South African grade 6 learners bring to the learning process as well as how they interact with the resources and practices that characterise the schools they attend. The research method is historiographic, offering insights into current conditions. An analysis of content is done through examining evidence gathered from an international project. Gender, socio-economic groupings and other major aspects associated with differences in mathematics achievement among learners and schools are addressed. An overall picture of contextual factors that may impact on mathematics achievement is presented. Although the essential conclusions of the investigation are largely straightforward, valuable contextual information emerged that may have implications for mathematics education within the context of South Africa as a developing country.

\section{Introduction}

This investigation is based on data collected on personal characteristics and academic attributes of gade 6 learners in South Africa. This article is a companion paper to An investigation into the mathematics performance of grade 6 learners in South Africa. In this series of two articles, the mathematics achievements of learners in South Africa are analysed. The research is based on an international project, the Southern and Eastern African Consortium for Monitoring Educational Quality (SACMEQ), a network of 15 countries from Southern and Eastern Africa aiming to monitor and evaluate the quality of their education systems.

To be mathematically literate implies that learners are able to identify, understand and engage in mathematics and to make well-founded judgements about the role that mathematics plays. Mathematical literacy also relates to an individual's capacity to use and engage with mathematics in ways that meet the needs of that individual's life as a constructive and reflective citizen (PISA, 2003: 7,15). These contexts for the use of mathematics address both external contexts ('situations' and 'the world') and internal contexts ('an individual's life' and 'everyday activity/ practice'). The former refers to the natural, social and cultural setting in which an individual lives in order to organise the phenomena of the physical, social and mental world (PISA, 2003: 25). The 'individual's life' may include personal experience in his or her private life, occupational life, social life with peers, relatives and others as well as life as a citizen of a community. Hence internal and external factors (such as personal, situational and cultural) that may contribute to the learning environment against which learners measure themselves are investigated.

\section{Aim and problem statement}

The aim of this article is to provide insight into the individual characteristics and family backgrounds that mathematics learners bring to the learning process and how they interact with the resources and practices that characterise the schools they attend.

In order to achieve the aim the following general questions are formulated:

- What aspects of grade 6 learners and their backgrounds - that is, personal and home-related characteristics of learners, including their family backgrounds such as the economic, social and cultural capital of learners and their families might impact upon these learners?

- What aspects of grade 6 learners' lives at school, including their habits and life inside school might have implications for learners - in other words, what aspects of the school context might impact upon these learners? 
Subsequently the following questions are posed regarding grade 6 mathematics learners in South Africa:

- What are the personal characteristics of the learners?

- What is the socio-economic context of the learners?

- What are the school context characteristics of the learners?

Information was gathered from learners concerning their attitudes, perceptions, backgrounds and in-and-out-of-school activities. This information was analysed and interpretations between regions and between low and high socioeconomic groups were made. Particular characteristics prevalent in different regions and differences between the approaches to learning of various groups, including male and female learners and those from less advantaged social backgrounds, were identified.

\section{Research design}

The research strategies implemented are partly historiographic (an effort is made to cast light on current conditions and problems through a deeper and fuller understanding of what has occurred in the past) and partly based on an analysis of content (sources of evidence are examined). The specific procedures of the conducting of the SACMEQ II survey comprised three parts, namely the development of the main phases, sample design procedures, and the construction of the tests (SACMEQ II Research Report, s.a.).

\section{Conceptualisation}

The social, political and economic contexts in which schooling takes place have a considerable impact on learning. Clarke (1996: 327) states that schools represent society's greatest collaborative enterprise because everyone has a stake. Knowledge, skills and values are influenced to a large extent by the kinds of interactions that take place between learners' personal characteristics and their social environment (Troutman \& Lichtenberg, 2003: 23).

Learners in South African schools come from extremely diverse social, political, economic and cultural backgrounds, and this can be linked to the concern about the mathematics education of South African learners

Learner diversity may be observed with regard to race, religion, ethnicity as well as other potential disadvantages and disabilities, and exceptional ability. Swart and Pettipher's classification (2005:
8) of diversity includes learners with exceptional intelligence; learners who are mentally impaired; gifted and talented learners; learners with specific learning disabilities; learners with physical challenges and chronic health problems; learners with communicative disorders; and learners with emotional and behavioural disorders. This learner diversity implies that provision should be made for unique needs in regular education classrooms.

Socio-economic characteristics span factors such as parent educational level, material possessions and the quality of the home environment. Socio-economic status relates to parental education, familial income, education, employment, books in the home and other similar indicators that are used to infer learners' social class that, in turn, has to do with diverse ethnic, racial and linguistic backgrounds (Troutman \& Lichtenberg, 2003: 26, 561).

Personal characteristics include aspects such as gender and age. Research studies reveal that there is considerable concern amongst the mathematics education research community regarding gender issues (Van de Walle, 2001: 459). The role of the family in shaping learners' beliefs and attitudes toward schooling in general and mathematics in particular is significant. This is strongly advocated by McLeod (1992: 587) who argues that mathematics education can benefit from careful analyses of cross-cultural comparisons on issues related to the social context of instruction. Eccles and Jacobs (in Leder, 1992: 613), in an examination of social determinants of mathematics attitude and performance, identify parents as a critical force and state that parents exert a more powerful and more direct effect than educators on learners' attitudes towards mathematics.

School context characteristics focus on learner engagement at school, especially on the practices that characterise the schools they attend. An important research conclusion (EFA, 2004) is that there are opportunities to significantly improve the ways human and material resources are managed and used in schools, recognising that the school is a complex institution that operates within a wider socio-cultural and political context. Contemporary changes in education, such as outcomes-based education, have resulted in a greater variation within the context of the mathematics classroom with respect to what is taught, as well as how and to whom it is taught. Naudé $(2004: 128,140)$ states that an effective learning environment provides opportunities for successful learning experiences, facilitates strategic planning, providing immediate 
feedback and reinforcement that eventually makes learners aware of the results of their efforts.

\section{Presentation and discussion of data}

Data were gathered from the nine provinces in the South African school system (SACMEQ II Research Report, s.a.). Where necessary codes were allocated to interpret certain variables in the tables, for example, recoded variables describe parents' level of education, the materials used in the construction of learners' homes, the number of books and reading materials, and the number of possessions in learners' homes, among others.

The desired target population definition for the SACMEQ II project was all grade 6 learners in 2000 (at the first week of the eighth month of the school year) who were attending registered mainstream primary schools (SACMEQ II Research Report, s.a.). Every result should be interpreted in terms of the standard error (SE). At national level, the average age of the grade 6 learner was 156,9 months (about 13 years and one month), in other words, the age of $95 \%$ of the population from which the sample was taken fell in the age mean $156,9 \pm 2(0,69)$ months. In terms of the age requirements for admission to an ordinary public school (turning seven in the year of admission to grade 1) it is expected that a learner in grade 6 who has not repeated a grade should be 12 years old (144 months) towards the completion of the grade 6 year. Thus, the grade 6 learner on average was one year older than the official norm (Table 1).

\begin{tabular}{|l|c|c|c|c|c|}
\hline \multirow{2}{*}{ Province } & \multicolumn{2}{|c|}{$\begin{array}{c}\text { Age } \\
\text { months) }\end{array}$} & \multicolumn{3}{|c|}{ Gender } \\
\cline { 2 - 6 } & Mean & SE & $\%$ & $\%$ & SE \\
\hline Eastern Cape & 164,2 & 2,03 & 50,9 & 49,1 & 2,60 \\
\hline Free State & 160,7 & 1,88 & 49,1 & 50,9 & 1,63 \\
\hline Gauteng & 151,4 & 1,54 & 47,3 & 52,7 & 3,72 \\
\hline KwaZulu Natal & 155,1 & 1,50 & 46,6 & 53,4 & 2,26 \\
\hline Mpumalanga & 160,6 & 1,85 & 51 & 49,0 & 1,69 \\
\hline Northern Cape & 159,7 & 2,76 & 54,2 & 45,8 & 3,66 \\
\hline Limpopo & 161,3 & 1,61 & 43,6 & 56,4 & 3,33 \\
\hline North West & 149,0 & 2,40 & 48 & 52,0 & 2,15 \\
\hline Western Cape & 149,5 & 1,14 & 43,8 & 56,2 & 2,47 \\
\hline South Africa & $\mathbf{1 5 6 , 9}$ & $\mathbf{0 , 6 9}$ & $\mathbf{4 7 , 5}$ & $\mathbf{5 2 , 5}$ & $\mathbf{1 , 0 0}$ \\
\hline
\end{tabular}

\section{Table 1.}

\section{Personal characteristics: age and gender}

The data concerning the age of learners also provide insight into initial enrolment at the officially prescribed age, regular attendance and the progression of most learners from one grade to another at the appropriate time so that everyone is able to complete the curriculum. Repetition may also account for over-aged learners.

In Table 1 the ratio in percentages of boys and girls who participated in the study is provided for the provinces, followed by the figure for South Africa overall.

The overall South African average for girls constituted $52,5 \%$ of the grade 6 learners. A relatively lower overall presentation of male grade 6 learners is observed. Further research into gender distribution in the education system may shed light on phenomena like these. In this paper the reasons for this grade 6 gender phenomenon will be merely speculative.

Socio-economic characteristics involve, among others, parents' level of education, quality of the home environment, and the quantity and quality of support given to their children. Table 2 reflects the level of education of learners' parents. The key to the codes was developed as follows: the index for the level of education was calculated by assigning a score of 1 for a parent who had no schooling or adult education. The score 2 was assigned for some primary education, 3 for completed primary education, 4 for some secondary education, 5 for completed secondary education and 6 for completed post-secondary or university education. To compare the education of a two-parent household with the education of a single parent situation, the average of the education of a home with two parents was calculated. The mean levels of education of the parents are presented in Table 2 on the following page.

The national mean level of parent education is 3,8 on a scale of 1 to 6 . This implies that the average grade 6 learner's parents did not complete secondary education. It may be concluded that the average grade 6 learner comes from a home where the parents lack basic secondary education. The generally low levels of education for parents may be ascribed to the education policy of the government before 1994. Quality and adequate education are envisaged for all South African learners with the implementation of outcomesbased education. The data reveal a dire need for Adult Basic Education and Training (ABET) programmes that provide education for young people beyond school-going age as well as adults.

In order to examine the impact that learners' home and social environments may have on academic achievement, some of the research instrument questions addressed the issue of educational resources in the home. Books play an important role in the development and education of 


\begin{tabular}{lcccccccc}
\hline \multirow{2}{*}{ Province } & $\begin{array}{c}\text { Parent Education } \\
\text { (Index) }\end{array}$ & \multicolumn{2}{c}{$\begin{array}{c}\text { Books at home } \\
\text { (Number of books) }\end{array}$} & \multicolumn{2}{c}{$\begin{array}{c}\text { Possessions at } \\
\text { home (Index) }\end{array}$} & \multicolumn{2}{c}{$\begin{array}{c}\text { General quality of } \\
\text { learners' homes } \\
\text { (Index) }\end{array}$} \\
\cline { 2 - 9 } & Mean & SE & Mean & SE & Mean & SE & Mean & SE \\
\hline Eastern Cape & 3,5 & 0,14 & 24,1 & 4,33 & 5,4 & 0,44 & 10,6 & 0,37 \\
Free State & 3,3 & 0,31 & 27,4 & 6,80 & 6,6 & 0,39 & 11,4 & 0,96 \\
Gauteng & 4,6 & 0,20 & 45,2 & 7,51 & 8,5 & 0,46 & 13,8 & 0,50 \\
KwaZulu Natal & 3,9 & 0,16 & 29,2 & 6,88 & 6,5 & 0,60 & 12,1 & 0,49 \\
Mpumalanga & 3,5 & 0,16 & 30,3 & 6,61 & 5,3 & 0,55 & 11,4 & 0,43 \\
Northern Cape & 3,6 & 0,18 & 12,0 & 2,92 & 6,7 & 0,35 & 11,0 & 0,52 \\
Limpopo & 3,5 & 0,14 & 37,8 & 6,45 & 5,2 & 0,51 & 10,6 & 0,36 \\
North West & 3,5 & 0,11 & 22,1 & 4,78 & 5,9 & 0,39 & 11,8 & 0,31 \\
Western Cape & 4,8 & 0,15 & 49,2 & 7,54 & 9,6 & 0,39 & 14,0 & 0,25 \\
\hline South Africa & $\mathbf{3 , 8}$ & $\mathbf{0 , 0 7}$ & $\mathbf{3 2 , 9}$ & $\mathbf{2 , 3 6}$ & $\mathbf{6 , 6}$ & $\mathbf{0 , 2 0}$ & $\mathbf{1 1 , 9}$ & $\mathbf{0 , 1 9}$ \\
\hline
\end{tabular}

Table 2. Socio-economic characteristics: parent education

a child. The number of books to which learners have access can influence their abilities. The average number of books that were reported to be available in learners' homes is reflected in Table 2.

To obtain an index of other possessions in the home, learners were asked to tick a given list of items. The list included: other reading materials and electronic media such as weekly or monthly magazines, daily newspapers, radio, television set, video cassette recorder, cassette player, telephone, refrigerator or freezer, car, motorcycle, bicycle, piped water, electricity, and a table to write on. Items were calculated ranging from a minimum of zero for no item ticked to a maximum of 13 if all the items were ticked. The mean index is presented in Table 2.

The national average for books in the home of the average grade 6 learner is more or less 33 books. The mean index for possessions in the home of an average grade 6 learner is 6,6 at national level. These results are in line with previous results linking educational levels with socio-economic status. The availability of books and the number of possessions at home correlate with the level of education of the parents or guardians and the economic ability to purchase books and possessions. Provinces that displayed fewer books and possessions in homes corresponded with those provinces that had lower levels of parent education.

The final aspect relating to socio-economic characteristics is the general quality of the home environment. This information is presented in Table 2. The parents' socio-economic status, as reflected by general housing conditions, was investigated. General housing conditions included lighting, the condition of floors, walls and roofs in learners' homes or where they stayed during the school week. For each of the aspects the minimum value of the index was 1 for absolutely basic or poor conditions, and the maximum was 4 if the conditions were perfect. Therefore, the minimum value of the index for general quality was 4 if all the aspects were absolutely basic or poor, and the maximum was 16 if all the aspects were perfect.

The national mean of the index was 11,9 on the scale from 4 to 16 . The extremes for the provinces were Western Cape $(14,0)$, Gauteng $(13,8)$ and KwaZulu Natal $(12,1)$ on the one end of the general quality scale. According to the interpretation of the allocated scores, this means that on average grade 6 learners in these provinces stayed in homes where the majority used a paraffin, oil or gas lamp; the majority of the floors were made of wood or cement but few had carpets; the majority of the walls were made of stone, metal or wood; while the majority of the roofs were grass thatch, mud, metal or asbestos, but few were tiles. On the lower end of the general quality scale were Northern Cape (11,0), Limpopo $(10,6)$ and Eastern Cape $(10,6)$. The scores indicate that on average grade 6 learners stayed in homes where the majority either had no light or used fire or candles. Learners in this category lived in homes where the majority of the floors were made of earth, clay or canvas; the majority of the walls were made of cardboard, plastic, canvas, reeds, sticks or grass, while only a few walls were of stones, mud bricks or wood. The majority of the roofs were cardboard, plastic, canvas, grass thatch or mud but few were cement or concrete. 


\begin{tabular}{|c|c|c|c|c|c|c|c|c|}
\hline \multirow{3}{*}{ Province } & \multicolumn{7}{|c|}{ Place where learners stay during the school week } \\
\cline { 2 - 10 } & Parent/Guardian & \multicolumn{2}{|c|}{ Relatives/Family } & \multicolumn{2}{c|}{ Hostel/Board } & \multicolumn{1}{c|}{ Self/Children } \\
\cline { 2 - 10 } & $\%$ & SE & $\%$ & SE & $\%$ & SE & $\%$ & SE \\
\hline Eastern Cape & 73,9 & 4,30 & 15,1 & 2,61 & 3,4 & 1,52 & 7,5 & 1,95 \\
\hline Free State & 73,0 & 6,64 & 14,2 & 3,70 & 2,2 & 1,61 & 10,6 & 3,98 \\
\hline Gauteng & 87,3 & 3,21 & 7,3 & 1,78 & 0,6 & 0,36 & 4,8 & 1,88 \\
\hline KwaZulu Natal & 82,4 & 4,33 & 9,6 & 1,95 & 3,7 & 1,80 & 4,4 & 1,40 \\
\hline Mpumalanga & 62,7 & 7,48 & 16,9 & 2,55 & 4,8 & 1,57 & 15,6 & 5,63 \\
\hline Northern Cape & 86,2 & 3,28 & 9,3 & 2,61 & 0,4 & 0,44 & 4,0 & 1,17 \\
\hline Limpopo & 70,8 & 6,29 & 9,8 & 2,35 & 8,8 & 3,33 & 10,6 & 2,63 \\
\hline North West & 79,2 & 5,31 & 14,9 & 3,47 & 2,4 & 1,71 & 3,6 & 2,12 \\
\hline Western Cape & 87,6 & 2,50 & 8,8 & 2,69 & 1,9 & 1,20 & 1,7 & 0,90 \\
\hline South Africa & $\mathbf{7 8 , 1}$ & $\mathbf{1 , 8 2}$ & $\mathbf{1 1 , 4}$ & $\mathbf{0 , 8 7}$ & $\mathbf{3 , 6}$ & $\mathbf{0 , 7 3}$ & $\mathbf{6 , 9}$ & $\mathbf{0 , 8 6}$ \\
\hline
\end{tabular}

Table 3. School context characteristics: after-school care

From the findings, it is evident that, to varying degrees, a significantly high percentage of the learners have to do homework in conditions that are not conducive to effective learning. Many learners live in conditions that expose them to the elements (cold and heat) and social hazards. From the analysis, it would appear that a considerable number of learners stayed in temporary informal settlements that have become a typical phenomenon around towns and large cities.

Another aspect in this category is the place where grade 6 learners stay during the school week. Learners had to respond to the following options: living in their parents'/legal guardians' home; staying with other relatives or another family member; living in hostel/boarding school accommodation or somewhere by themselves or with other children. The findings are presented in Table 3.

The modal place of residence was a home with parents or legal guardians. A further $11,4 \%$ of the learners stayed with relatives or another family member, while $3,9 \%$ stayed in a hostel or in boarding school accommodation. However, 6,9\% of grade 6 learners either stayed on their own or with other children. Fairly high percentages of learners from Mpumalanga (15,6\%), Free State $(10,6 \%)$ and Limpopo $(10,6 \%)$ indicated that they stayed on their own. The latter learners are deprived of parental care, support and assistance with homework, which might influence their learning and attendance of school.

The next aspect addresses learners' absenteeism. Learners were asked to write down the number of days that they were absent during the month preceding the survey. Subsequently they had to provide a reason for their absence, choosing from the following options. These responses are reflected in Table 4 together with the data concerning the repetition of grades.

Table 4: Absenteeism and reasons

\begin{tabular}{|c|c|c|c|c|c|c|c|c|c|c|}
\hline \multirow{2}{*}{ Province } & \multicolumn{2}{|c|}{ Days absent } & \multicolumn{2}{|c|}{ Illness } & \multicolumn{2}{|c|}{ Family reasons } & \multicolumn{2}{|c|}{ School fees } & \multicolumn{2}{|c|}{ Work } \\
\hline & Mean & SE & $\%$ & SE & $\%$ & $\mathrm{SE}$ & $\%$ & SE & $\%$ & $\mathrm{SE}$ \\
\hline Eastern Cape & 1,4 & 0,21 & 21,2 & 2,6 & 10,6 & 2,78 & 4,8 & 1,53 & 6,2 & 1,13 \\
\hline Free State & 1,4 & 0,21 & 25,4 & 5,96 & 10,6 & 3,02 & 1,3 & 0,65 & 4,3 & 1,59 \\
\hline Gauteng & 1,0 & 0,27 & 16,9 & 2,58 & 4,9 & 1,6 & 1,5 & 0,77 & 1,1 & 0,59 \\
\hline KwaZulu Natal & 2,2 & 0,40 & 37,7 & 3,98 & 10,6 & 2,08 & 1,7 & 0,78 & 3,7 & 1,47 \\
\hline Mpumalanga & 1,9 & 0,33 & 25,5 & 5,42 & 8,5 & 2,05 & 5,2 & 2,24 & 9,2 & 2,52 \\
\hline Northern Cape & 1,5 & 0,25 & 33,8 & 3,82 & 5,5 & 2,36 & 3 & 1,29 & 3,8 & 1,39 \\
\hline Limpopo & 2,2 & 0,39 & 20,1 & 3,58 & 8,8 & 1,64 & 6,2 & 1,87 & 9,9 & 2,19 \\
\hline North West & 0,6 & 0,11 & 15,8 & 3,16 & 4,8 & 1,43 & 1,7 & 0,76 & 3,1 & 1,18 \\
\hline Western Cape & 1,6 & 0,45 & 26,1 & 4,64 & 13,5 & 3,98 & 0 & 0 & 1,5 & 0,96 \\
\hline South Africa & 1,6 & 0,13 & 24,6 & 1,4 & 9 & 0,86 & 3 & 0,47 & 4,9 & $\mathbf{0 , 5 7}$ \\
\hline
\end{tabular}


The overall South African mean for days absent was 1,6 days per month. With regard to absenteeism at the national level the learners had been absent for an average of two days, which translated into an average of $10 \%$ of school days. The main reason for absence was 'illness', followed by 'family reasons' and then 'work they had to do at home'. The payment of school fees did not play an important role in learner absenteeism.

Information concerning mathematics issues (the frequency with which learners received mathematics to be done and practised at home) is addressed next. Table 5 summarises the relevant data.

\begin{tabular}{lcccccccc}
\hline Province & $\begin{array}{l}\text { Receiving } \\
\text { mathematics } \\
\text { homework }\end{array}$ & \multicolumn{3}{c}{$\begin{array}{l}\text { Home assistance 'most of the time' with } \\
\text { school work }\end{array}$} & $\begin{array}{l}\text { Own mathematics } \\
\text { Do mathematical } \\
\text { calculations }\end{array}$ & $\begin{array}{l}\text { Questions on } \\
\text { textbook } \\
\text { mathematics }\end{array}$ & & \\
\cline { 2 - 6 } & $\%$ & SE & $\%$ & SE & $\%$ & SE & $\%$ & SE \\
\hline Eastern Cape & 48,7 & 4,82 & 30,5 & 3,98 & 28,9 & 2,40 & 42,3 & 4,85 \\
Free State & 54,8 & 10,94 & 26,1 & 7,66 & 29,6 & 7,59 & 49,1 & 12,36 \\
Gauteng & 58,5 & 8,67 & 24,6 & 3,99 & 27,5 & 4,58 & 51,1 & 13,55 \\
KwaZulu Natal & 46,2 & 6,31 & 29,3 & 5,40 & 34,9 & 4,86 & 39,9 & 7,69 \\
Mpumalanga & 50,2 & 6,36 & 38,9 & 3,70 & 37,7 & 4,52 & 34,6 & 6,63 \\
Northern Cape & 43,4 & 5,90 & 27,4 & 4,84 & 26,5 & 4,00 & 28,4 & 7,25 \\
Limpopo & 62,8 & 5,48 & 25,4 & 2,40 & 33,6 & 3,09 & 43,1 & 7,52 \\
North West & 43,3 & 6,40 & 33,8 & 4,55 & 32,3 & 4,00 & 24,7 & 6,49 \\
Western Cape & 70,6 & 5,16 & 30,9 & 6,74 & 27,6 & 6,35 & 36,9 & 9,37 \\
\hline South Africa & $\mathbf{5 3 , 8}$ & $\mathbf{2 , 4 1}$ & $\mathbf{2 9 , 2}$ & $\mathbf{1 , 7 1}$ & $\mathbf{3 1 , 4}$ & $\mathbf{1 , 6 3}$ & $\mathbf{4 1 , 1}$ & $\mathbf{3 , 0 0}$ \\
\hline
\end{tabular}

Table 5. Learners' involvement with mathematics homework

The overall South African percentage for home involvement in mathematics homework is $53,8 \%$. This reflects the extent to which homework is valued and the extent to which understanding of what was taught during class is consolidated. However, doing homework also avails learners of an important opportunity to interact with family members over their schoolwork and, through these interactions, learners receive a wider spectrum of perspectives.

Grade 6 learners' responses to whether they received mathematical assistance at home 'most of the time' are indicated in Table 5. Overall, for South Africa, the levels of home assistance with mathematics were noticeably low. The national averages for assistance at home with mathematical calculations was $29,2 \%$ while a similar pattern is reflected concerning questions on school mathematics work to be done at home $(31,4 \%)$.

The generally low levels of assistance that learners received from family members correlate with the low levels of parents' educational backgrounds, as pointed out earlier. Parents seem to have attained low levels of schooling and, therefore, may not feel competent enough to render the necessary assistance. The low levels of education may also influence the interest that parents take in their children's schoolwork.
Finally, information was gathered to determine whether learners had sufficient access to classroom materials to participate meaningfully in their lessons. The question concerning the possession of mathematics textbooks is addressed in Table 5.

For South Africa overall, 41,1\% of grade 6 learners had their own mathematics textbooks. The distribution varied among the provinces with the highest average in the Free State and the lowest in Northern Cape. Generally, the percentage of books owned or available to individual learners was very low. This phenomenon had a direct influence on practicing mathematics at home as not all learners could refer to their textbooks. Mathematics to be done at home was normally written down on the chalkboard and copied by the learners. This is not the ideal way of spending teaching time in a mathematics classroom.

\section{Findings and conclusion}

Answers were sought to three major questions regarding the impact that personal characteristics, socio-economic aspects and school context characteristics might have upon grade 6 mathematics learners. From the data gathered, certain insights emerge. 
A considerable number of learners were overaged (about one year older than was expected for a grade 6 learner if they started school at the official age of seven years and had not repeated a grade). This may be ascribed to possible delayed enrolment and/or grade repetition. This may imply that major changes in school system organisation and improvements in teaching quality is needed.

Although girls $(52,5 \%)$ outnumbered boys $(47,5 \%)$, with the exception of a few provinces it seems as if gender imbalances are not a major issue. Gender disparity at this level of schooling is not prevalent. However, disparities between the sexes are usually more prevalent in secondary and higher education than in primary education (EFA, 2004: 103). It may be argued that mathematics acts as a gatekeeper in depriving women and minority students of equal opportunities in further education and employment. Contemporarily, gender issues focus on ensuring girls equal access to education resulting in gender parity and equality in education.

The majority of the learners (78\%) stayed with parents whose average education was mainly primary and barely secondary. It is generally accepted that higher education levels of parents foster a greater appreciation of the value of education and an ability to help children learn. The average grade 6 learner lived in a home where there were little more than 30 books. This low availability of books in homes can be related to the level of education of the parents or guardians and the economic ability to purchase books. These results also correlate with the number of possessions at home where the mean for possessions at the home of an average grade 6 learner was just under 7 on a scale of 13 at the national level with a noticeable drop in the number of possessions in rural settings in comparison with urban environments.

Data gathered with regard to the general quality of grade 6 learners' homes reveal that a considerable number of learners stay in informal settlements. Conditions in such migrant settlements are not conducive to effective learning and may impact upon learners' schoolwork. A sizeable number of learners (about 7\%) indicated that they stayed either on their own or with friends during the school week.

The socio-economic backgrounds of learners underline other educational research findings (Van de Walle, 2001: 456). Khuzwayo's research (2005: 313) indicates that learners from higher socioeconomic backgrounds tend to perform better on tests of educational achievement than those from poorer backgrounds - mainly because children from wealthier homes have greater access to a range of human and material resources that enhance, facilitate and reward school learning. Also, in more affluent areas where parents can afford to pay extra, data reveal positive results such as the acquisition of social and analytic skills by learners. Research about the nature of differences (social class, race, ethnicity, language background, gender and other demographic characteristics) is needed to help schools better educate a portion of the population that is growing. Keitel (2005: 330) advocates alternative forms of mathematics education research in which greater focus is placed on socio-cultural aspects of learning.

The provinces with the highest absenteeism rates were Limpopo, KwaZulu Natal and Mpumalanga. In view of the contemporary impact of the HIV/AIDS pandemic in Africa, this tendency of illness needs to be monitored so that appropriate measures can be taken.

General support of and interest in learners' academic activities were moderate. The average percentages were as follows: for ensuring that homework was done, 18,4\%; assistance with homework, 34,5\%; and interest in completion of schoolwork at home, 39\%. Homework provides an opportunity to enhance academic development and more time devoted to homework usually results in higher scores. Less than half of the grade 6 learners $(41,1 \%)$ owned a mathematics textbook. The problem was most acute in rural provinces.

In conclusion, there were major differences between the nine provinces; between low and high socio-economic groups and between rural and urban schools. Particular characteristics prevalent in certain provinces as well as differences between various groups emerged from the data. In the second article in this series, correlations between certain variables and achievement will be addressed.

The essential conclusions of this investigation are:

- To understand the diverse needs of learners especially multiple disadvantaged learners in a developing country.

- To focus on the place where teaching and learning actually takes place - the classroom.

- To point out that the cognitive value added by schooling (as opposed to home background) should not be underestimated. 
Although these conclusions are largely straightforward, they have implications for mathematics performance that will be addressed in the second article. Compared to the vision of quality education, access and equity of Education for All (World declaration on education for all, 2004) the results of the investigation indicate that much more should be done to ensure that children learn to a sufficient level to perform well as future citizens.

\section{References}

Clarke, D. (1996). Assessment. In A.J. Bishop, K. Clements, C. Keitel, J. Kilpatrick, and C. Laborde (Eds.), International handbook of mathematics education (pp 327-370). London: Kluwer 1.

Education for All (EFA). (2004). Global Monitoring Report. Paris:UNESCO.

Keitel, C. (2005). Reflections on mathematics education research in South Africa. In Renuka Vithall, Jill Adler \& Christine Keitel (Eds.), Researching mathematics education in South Africa (pp 329-344). Cape Town: HSRC Press.

Khuzwayo B a history of mathematics educarion research in South Africa: the apartheid years. In Renuka Vithall, Jill Adler \& Christine Keitel (Eds.), Researching mathematics education in South Africa (pp 307-327). Cape Town: HSRC Press.
Leder, G.C. (1992). Mathematics and gender: changing perspectives In Douglas A Grouws (Ed.), Handbook of research on mathematics teaching and learning (pp 597-622). New York: MacMillan.

McLeod, D.B. (1992). Research on affect in mathematics education: a reconceptualization. In Douglas A Grouws (Ed.), Handbook of research on mathematics teaching and learning (pp 575-596). New York: MacMillan.

Naudé, D. (2004). Acquisition of mathematics literacy. In Irma Eloff \& Liesel Ebersohn (Eds). Keys to educational psychology (pp 119-144). Cape Town: UCT Press.

Programme for International Student Assessment (PISA). (2003). Retrieved November 11, 2004, from http://www.pisa.gc/math

SACMEQ II Research Report s.a. (forthcoming). Paris: UNESCO.

Swart, E., \& Pettipher, R. (2005). A framework for inclusion. In E. Landsberg, E. Kruger \& N. Nel (Eds.), Addressing barriers to learning (pp 323). Pretoria: Van Schaik.

Troutman, A.P., \& Lichtenberg, B.K. (2003). Mathematics - a good beginning. Belmont: Thompson-Wadsworth.

Van de Walle. J.A. (2001). Elementary and middle school mathematics. New York: Longman.

For the things of this world cannot be made known without a knowledge of mathematics.

Roger Bacon 